\title{
Commercialization of Big Area Additive Manufacturing
}

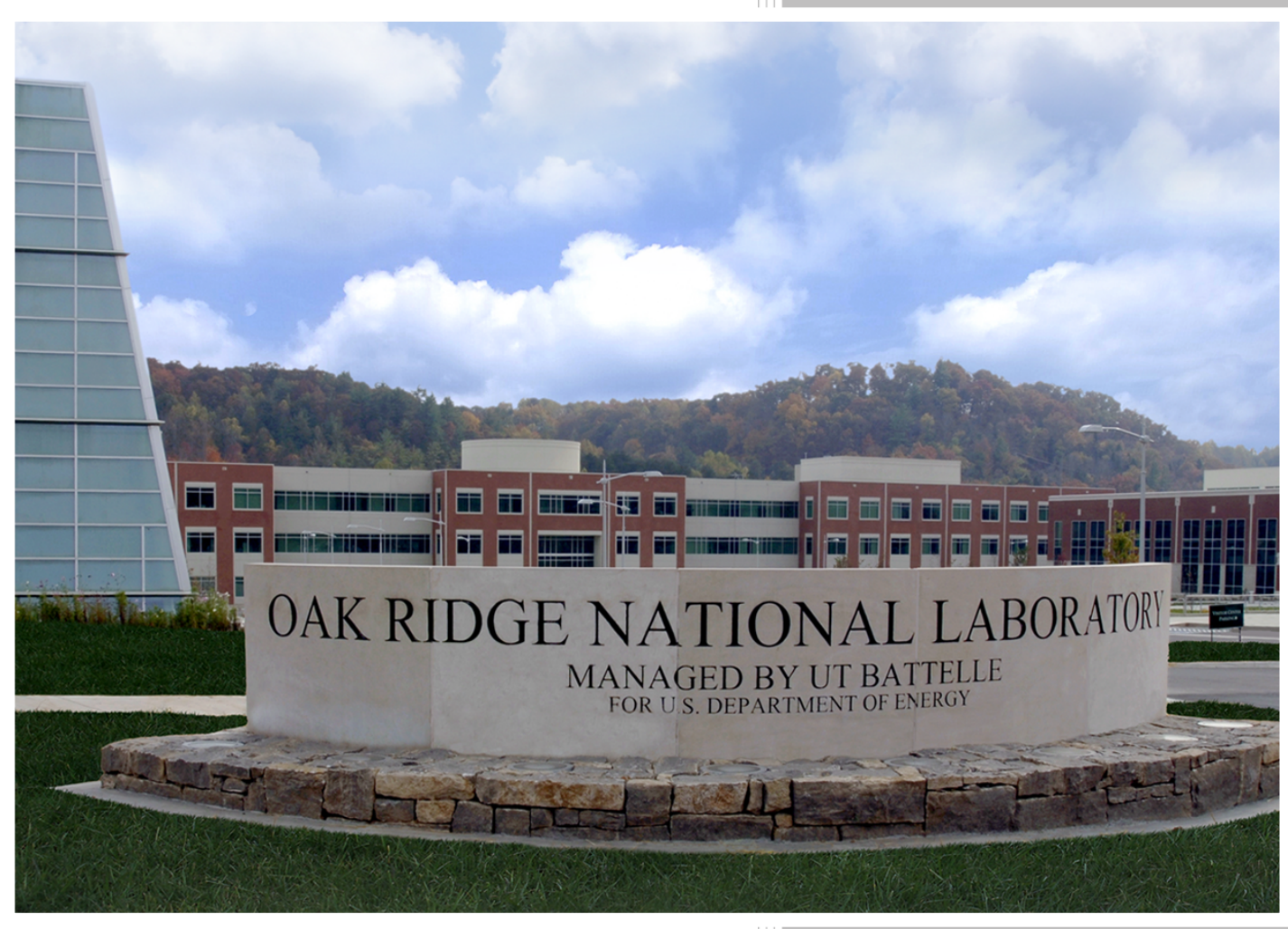

Lonnie Love

Brian Post

Vlastimil Kunc

Alex Roschli

March 2020

CRADA FINAL REPORT

NFE-16-06083

Approved for Public Release.

Distribution is Unlimited.

OAK RIDGE NATIONAL LABORATORY 


\title{
DOCUMENT AVAILABILITY
}

Reports produced after January 1, 1996, are generally available free via US Department of Energy (DOE) SciTech Connect.

Website www.osti.gov

Reports produced before January 1, 1996, may be purchased by members of the public from the following source:

\author{
National Technical Information Service \\ 5285 Port Royal Road \\ Springfield, VA 22161 \\ Telephone 703-605-6000 (1-800-553-6847) \\ TDD 703-487-4639 \\ Fax 703-605-6900 \\ E-mail info@ntis.gov \\ Website http://classic.ntis.gov/
}

Reports are available to DOE employees, DOE contractors, Energy Technology Data Exchange representatives, and International Nuclear Information System representatives from the following source:

Office of Scientific and Technical Information

PO Box 62

Oak Ridge, TN 37831

Telephone 865-576-8401

Fax 865-576-5728

E-mail reports@osti.gov

Website http://www.osti.gov/contact.html

\begin{abstract}
This report was prepared as an account of work sponsored by an agency of the United States Government. Neither the United States Government nor any agency thereof, nor any of their employees, makes any warranty, express or implied, or assumes any legal liability or responsibility for the accuracy, completeness, or usefulness of any information, apparatus, product, or process disclosed, or represents that its use would not infringe privately owned rights. Reference herein to any specific commercial product, process, or service by trade name, trademark, manufacturer, or otherwise, does not necessarily constitute or imply its endorsement, recommendation, or favoring by the United States Government or any agency thereof. The views and opinions of authors expressed herein do not necessarily state or reflect those of the United States Government or any agency thereof.
\end{abstract}


ORNL/TM-2020/1454

CRADA/NFE-16-06083

Energy and Transportation Science Division

Advanced Manufacturing Office

\title{
Commercialization of Big Area Additive Manufacturing
}

\author{
Authors \\ Lonnie Love \\ Brian Post \\ Vlastimil Kunc \\ Alex Roschli \\ Date Published: \\ March 2020 \\ Prepared by \\ OAK RIDGE NATIONAL LABORATORY \\ Oak Ridge, Tennessee 37831-6283 \\ managed by \\ UT-BATTELLE, LLC \\ for the \\ US DEPARTMENT OF ENERGY \\ under contract DE-AC05-00OR22725
}

Approved For Public Release 



\section{CONTENTS}

PAGE

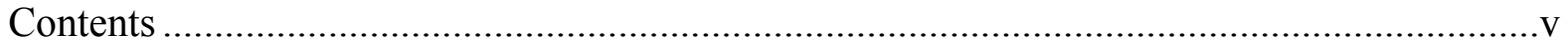

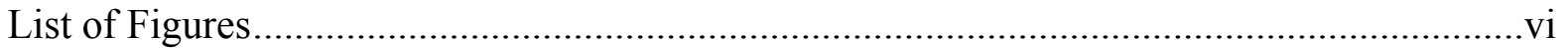

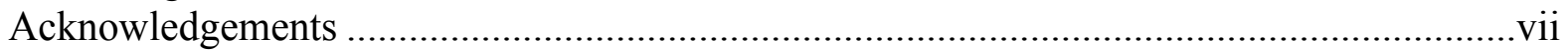

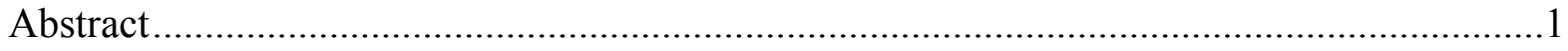

1. Commercialization of Big Area additive Manufacturing ..............................................1

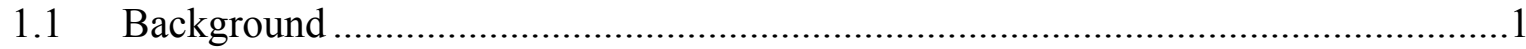

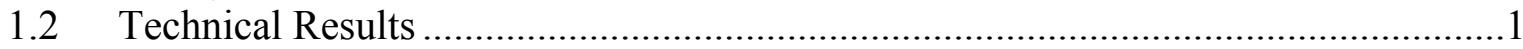

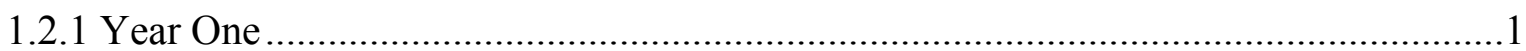

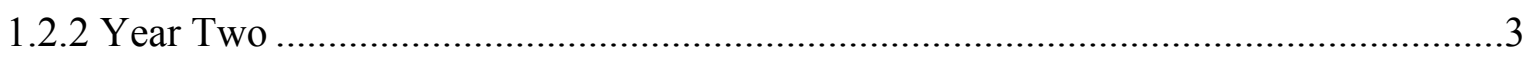

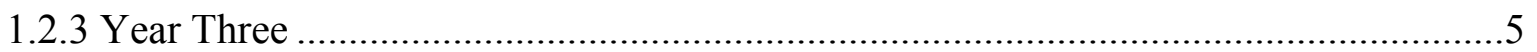

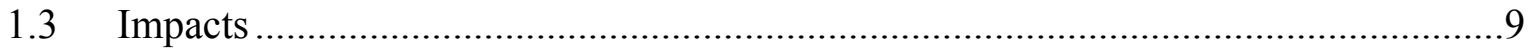

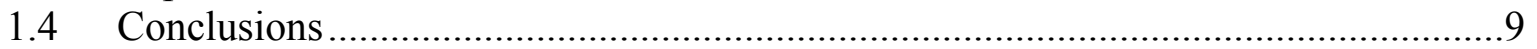

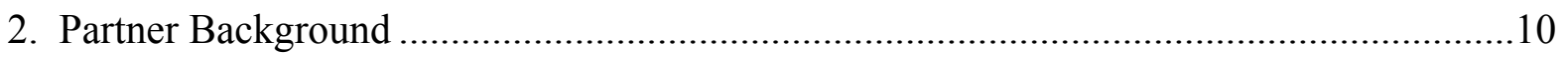




\section{LIST OF FIGURES}

Figure 1. Dryer interface on BAAM showing system faults and material low alarm ..............2

Figure 2. BAAM IR camera at the end of a pneumatic arm for extending/retracting ..............2

Figure 3. Underfilling during the printing of a hexagon ....................................................

Figure 4. Hexagon from Figure [3] after the computer detected and corrected the underfill....3

Figure 5. Printing a $90^{\circ}$ corner without the system ID model ............................................

Figure 6. Printing a $90^{\circ}$ corner with the system ID model ............................................

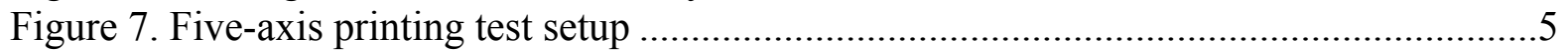

Figure 8. Successful print showing out-of-plane printing .............................................5

Figure 9. Magazine for holding sensors on the left and magazine for holding tracker pucks on

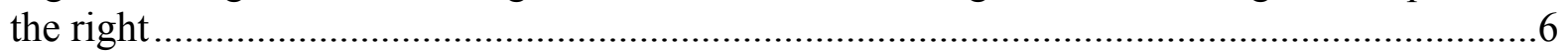

Figure 10. Tracker ball puck emplaced during a print....................................................6

Figure 11. Multi-material system installed on BAAM ............................................... 7

Figure 12. A two-color oak leaf printed using the multi-material system .............................

Figure 13. Dual Port Nozzle assembly ....................................................................

Figure 14. A print with the dual port nozzle showing high resolution exterior and low

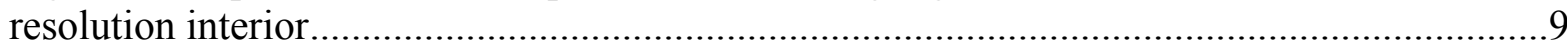




\section{ACKNOWLEDGEMENTS}

This CRADA NFE-16-06083 was conducted as a Technical Collaboration project within the Oak Ridge National Laboratory (ORNL) Manufacturing Demonstration Facility (MDF) sponsored by the US Department of Energy Advanced Manufacturing Office (CPS Agreement Number 24761).

Opportunities for MDF technical collaborations are listed in the announcement "Manufacturing Demonstration Facility Technology Collaborations for US Manufacturers in Advanced

Manufacturing and Materials Technologies" posted at http:/web.ornl.gov/sci/manufacturing/docs/FBO-ORNL-MDF-2013-2.pdf. The goal of technical collaborations is to engage industry partners to participate in short-term, collaborative projects within the Manufacturing Demonstration Facility (MDF) to assess applicability and of new energy efficient manufacturing technologies. Research sponsored by the U.S. Department of Energy, Office of Energy Efficiency and Renewable Energy, Advanced Manufacturing Office, under contract DE-AC0500OR22725 with UT-Battelle, LLC. 


\begin{abstract}
Oak Ridge National Laboratory (ORNL) first partnered with Cincinnati Incorporated (CI) through a Cooperative Research and Development Agreement (CRADA) (NFE-14-04957) in 2014 to demonstrate the feasibility and viability of Big Area Additive Manufacturing (BAAM). The first CRADA was a success and paved the way for large format additive manufacturing (LFAM). ORNL and CI partnered again for this second CRADA (NFE-16-06083) to improve process control, enhance printing capabilities, and shift towards production capability.
\end{abstract}

\title{
1. COMMERCIALIZATION OF BIG AREA ADDITIVE MANUFACTURING
}

This collaboration began on April 21, 2016 and concluded on December 21, 2019. The collaboration partner Cincinnati, Incorporated is a small business. This second CRADA (NFE-16-06083) with CI resulted in new software/hardware for fault detection, multi-nozzle printing, 5-axis deposition, pick and place capabilities, and multi-material capabilities on CI's polymer BAAM system.

\subsection{BACKGROUND}

ORNL and CI first partnered in 2014 via CRADA (NFE-14-04957) to develop the BAAM system by converting CI's existing laser cutter platform into a large format 3D printer. CI delivered a $2 \mathrm{~m} \mathrm{x} \mathrm{4m} \mathrm{x}$ $1 \mathrm{~m}$ development platform to ORNL in early 2014. ORNL successfully integrated a polymer extruder to the system and went on to produce the World's First 3D Printed Car at the International Manufacturing Technology Show later that same year. The remainder of the first CRADA focused on proving that BAAM was viable. CI was able to turn BAAM into a commercial product and began machine sales during the first CRADA. More information about the results of the first CRADA can be found in the Technical Report (DOI: 10.2172/1210140).

This second CRADA between ORNL and CI is focused on further developing BAAM and improving its capabilities. While BAAM is a commercially available product with more than a dozen machines in the field, work still remains to further improve the process. The CRADA is broken down into three years with individual tasks for each year. The first year is focused on process control with emphasis on detecting and managing faults during the print process. The second year is focused on enhancing the printing capabilities with layer to layer inspection, high speed printing, and five-axis deposition. The third and final year is about improved production capabilities including integrated pick and place, multi-nozzle printing, and multi-material printing.

\subsection{TECHNICAL RESULTS}

\subsubsection{YEAR ONE}

In the first year, ORNL focused on sensing and controls to improve the printing process. ORNL was tasked with determining the different types of machine faults that could occur and implementing solutions to mitigate these faults. One fault was the loss of material feed. This fault can be caused by the dryer going empty (low material) or the feed system being unable to send material to the extruder. The low material issue was solved by wiring the dryer system into the BAAM so that the BAAM 
would know when material was low. This can bee seen in Figure [1]. In the instance of material not feeding to the head, this issue would usually have one minute to be fixed during a print or the print would fail due to an empty extruder. To quickly alert the operator, or any users that may be nearby, an audible siren was added to the system so that the issue could quickly be detected and resolved.

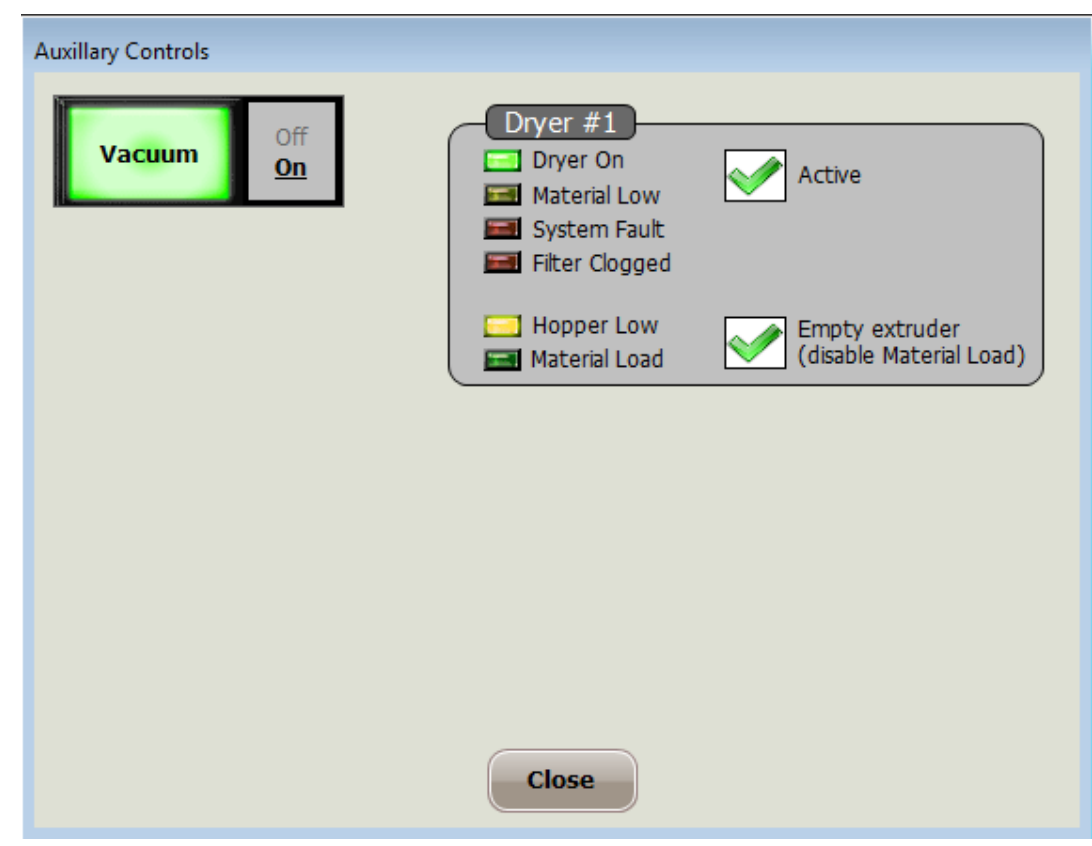

Figure 1. Dryer interface on BAAM showing system faults and material low alarm

Another fault encountered by the BAAM system comes from the printed object getting too hot or too cold during the print. If a print is going too fast, the temperature of the part gets too high and it can sag/droop and fail. If the print is too slow, the part gets too cold and the layers can delaminate or separate from one another. To resolve this issue, an IR camera was added to the BAAM system so that the system could monitor the layer temperature at the end of each layer. If the object is too hot, the machine pauses and waits for the object to cool. If the object is too cold, the system can notify the user of the issue so that the part can be printed faster, or stopped and redesigned. Figure [2] shows the IR camera assembly on BAAM.

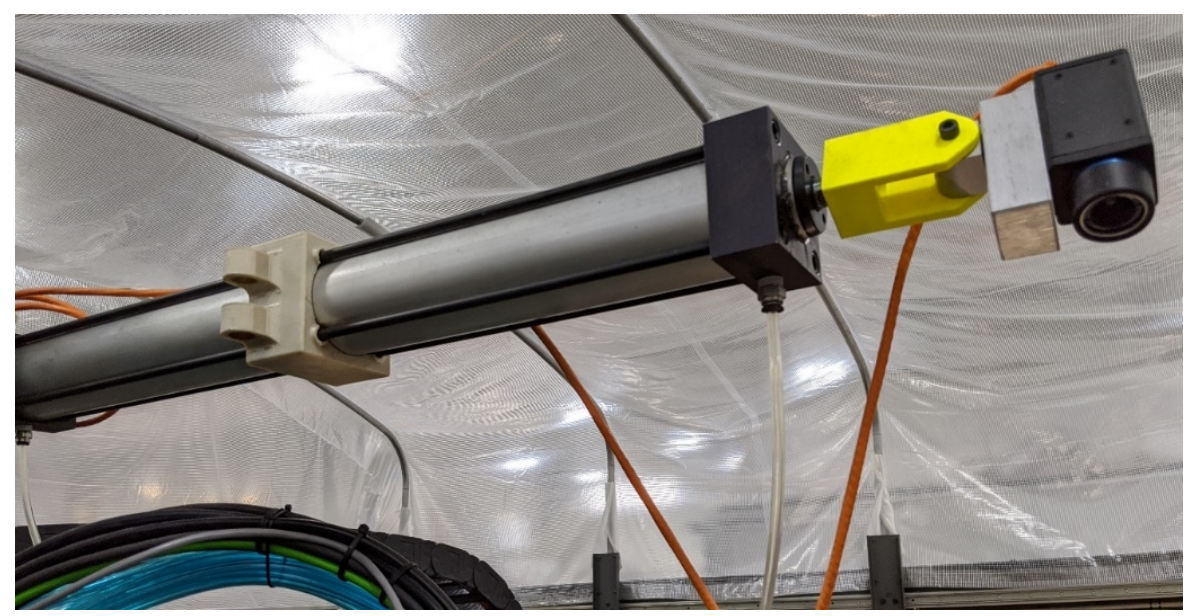

Figure 2. BAAM IR camera at the end of a pneumatic arm for extending/retracting 


\subsubsection{YEAR TWO}

In the second year, ORNL focused on layer to layer inspection, high speed printing, and five-axis deposition. Layer to layer inspection is important for detecting anomalies during the print. These could be areas of overfill, underfill, or a bead falling off an overhang. It's very easy for a human to see and detect these issues as they occur, but the goal is to have a system that autonomously detects the issues and corrects for them in real time. In order to give the machine the ability to see these defects, a new sensor had to be added to BAAM, a laser line scanner. The laser line scanner uses a laser to scan the top of each layer after it has been printed and compare the scan data to the layer plan from the slicer. Areas of underfill can be reprinted and areas of overfill can be under extruded, or skipped, on the next layer to compensate for the extra material. Figure [3] shows a layer with underfilling and Figure [4] shows that same object after the BAAM has autonomously compensated for the underfilling.

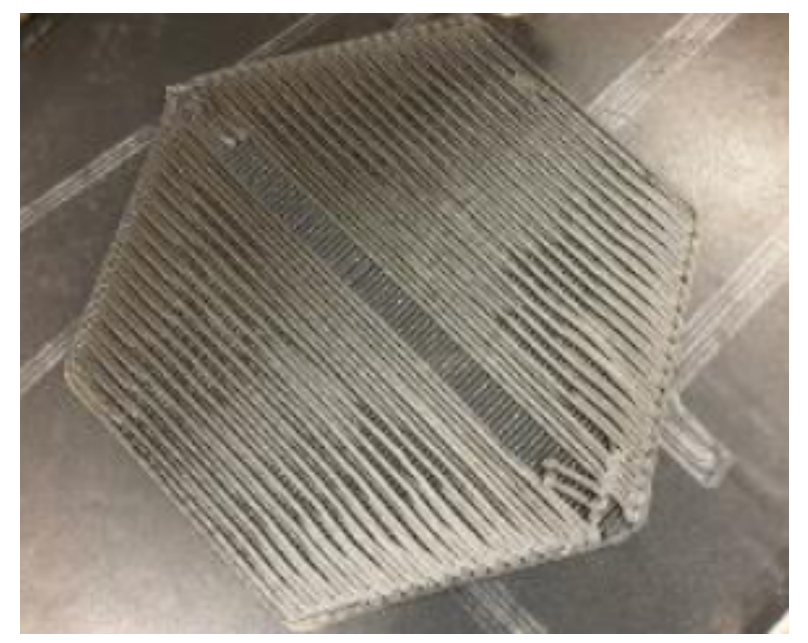

Figure 3. Underfilling during the printing of a hexagon

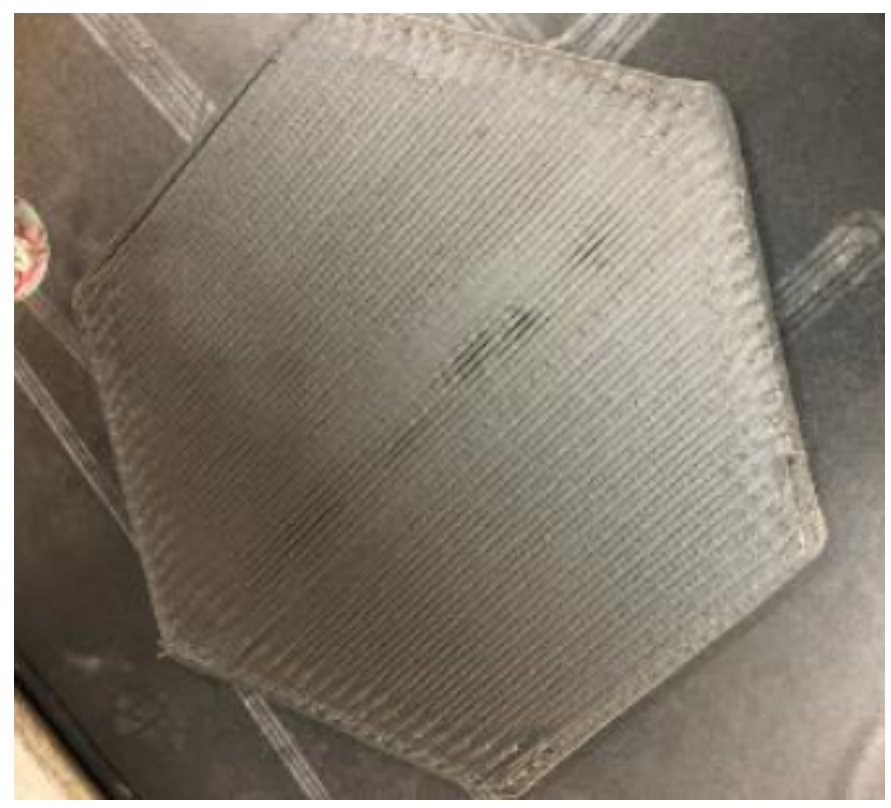

Figure 4. Hexagon from Figure [3] after the computer detected and corrected the underfill High speed printing at high resolution requires very accurate tuning of the BAAM system. The 
extruder must be able to operate at maximum speed while accurately tracking the quick accelerations and decelerations of the gantry system. To help better control the extruder through the various moves of the printing process, the system ID for the extruder needed to be calculated. This was done by printing a basic shape many times and forcing unique failures with each print, such as over accelerating or over decelerating the extruder, then measuring the extruded beam geometry. After many prints and many test cases, an accurate system ID was able to be fit to the observed extruder performance. This was then converted to a first-order model and implemented into the control system on BAAM. To prove the accuracy of the model, a print was conducted with and without the model to see how the bead geometry changed.

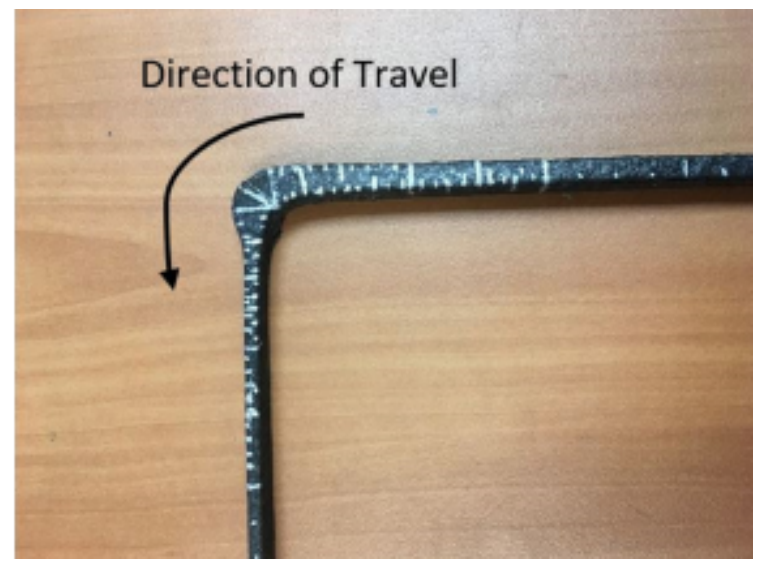

Figure 5. Printing a $90^{\circ}$ corner without the system ID model

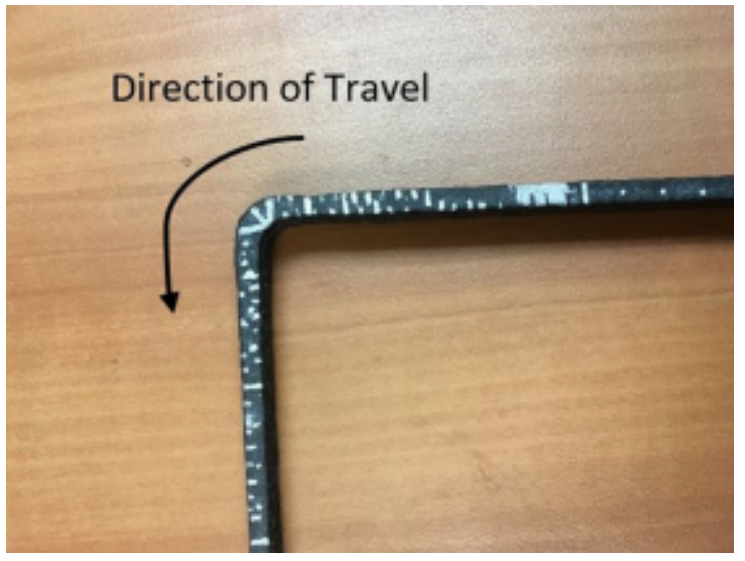

Figure 6. Printing a $90^{\circ}$ corner with the system ID model

Five-axis deposition gives the ability to print out-of-plane. Currently, the BAAM system only has three-axis deposition capability. To accomplish five-axis, a new system was needed to allow the nozzle to actuate in two axes, specifically roll and yaw movements. For this, a new system was constructed that would attach to the bottom of the extruder. The standard fixed nozzle was replaced with a flexible heated hose that can be manipulated in the roll and yaw axes to give the five-axis printing control. Figure [7] shows the test setup and Figure [8] shows a successful print with out-ofplane deposition. 


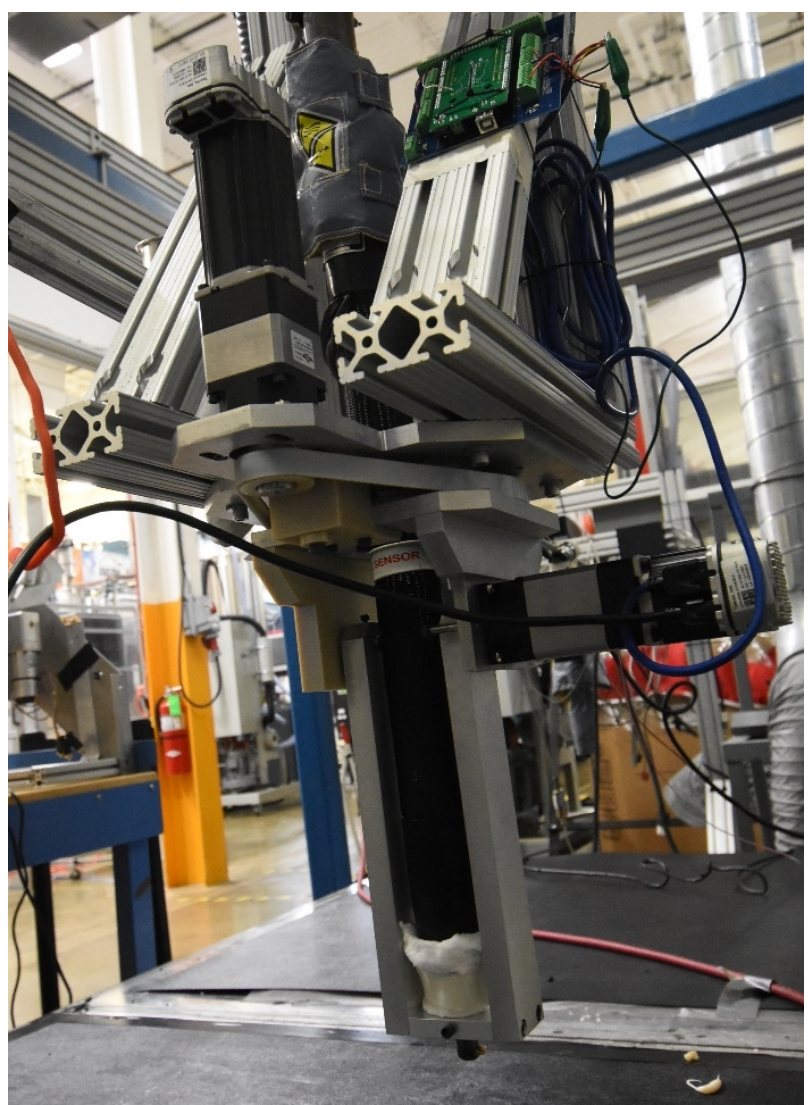

Figure 7. Five-axis printing test setup

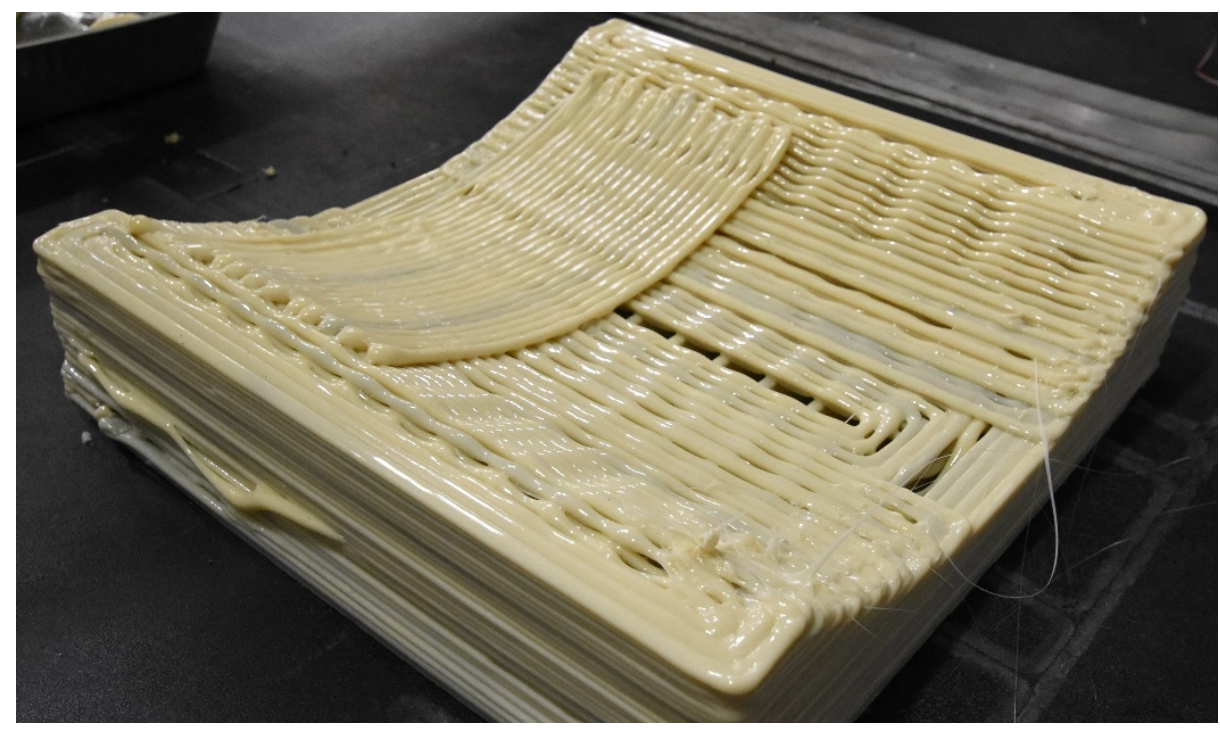

Figure 8. Successful print showing out-of-plane printing

\subsubsection{YEAR THREE}

In the final year, ORNL focused on hardware improvements to enhance the production capability of BAAM. The first of these, is integrated pick and place. A pick and place system is a form of robotics where a robot picks up an object and places it into a new location. These are useful for assembly lines 
where items need to be stacked or loaded into a box. For BAAM, pick and place is useful for emplacing sensors into a printed part during the printing process. To do this, ORNL developed a special pneumatic gripper to grasp objects, such as radio-frequency identification (RFID) tags and tooling ball mounts, and place them into the print during the build. Figure [9] shows the magazines holding sensors to be picked and Figure [10] shows an object with objects placed during printing.

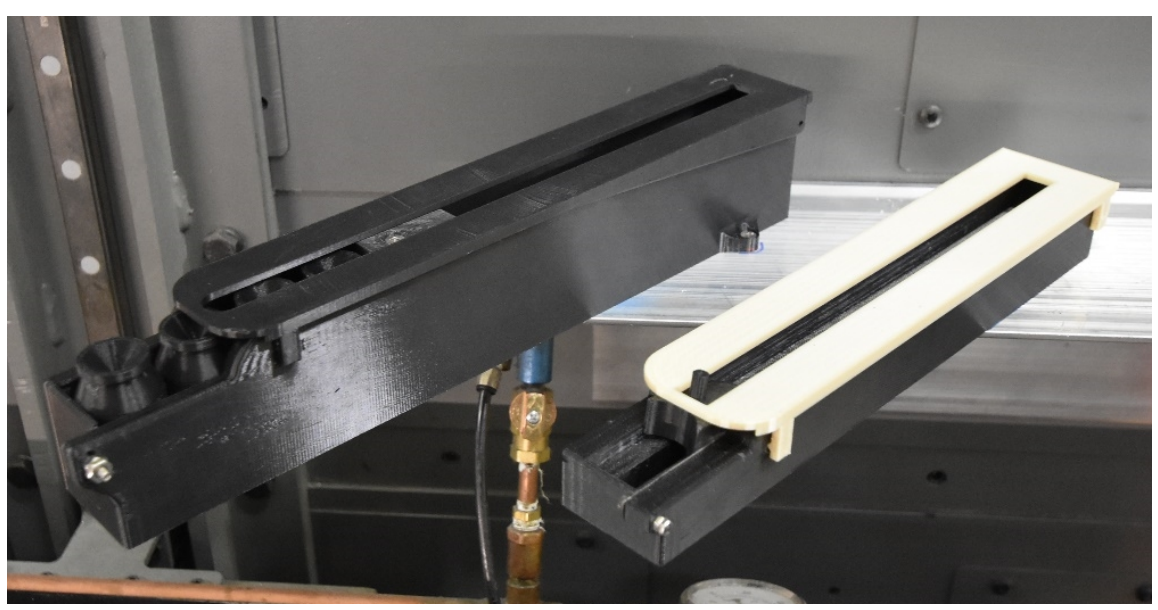

Figure 9. Magazine for holding sensors on the left and magazine for holding tracker pucks on the right

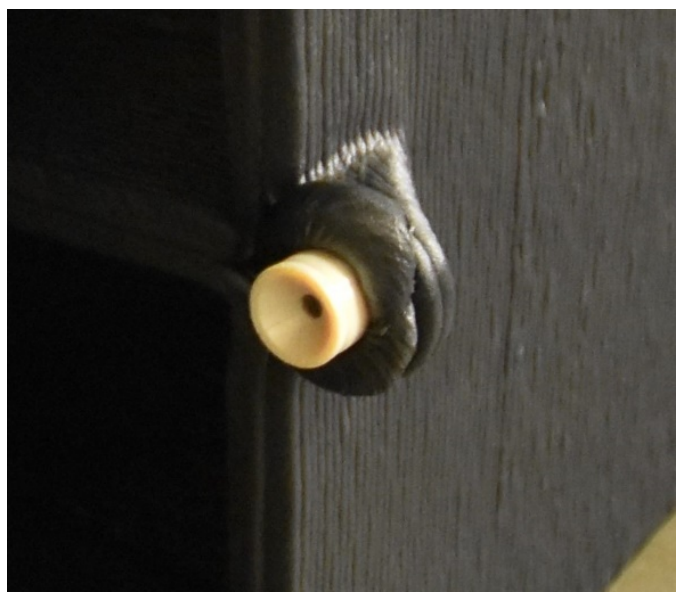

Figure 10. Tracker ball puck emplaced during a print

Also in the third year, ORNL developed a system to allow for multi-material printing. The BAAM system only has one extruder, and the traditional way to do multi-material printing on small-scale additive manufacturing systems is to use multiple extruders each with a different material. On BAAM, implementing additional extruders is very difficult because of the added weight and complexity of each extruder. ORNL came up with a different solution that involved two pellet feed lines coming to the inlet of the extruder. From the G-Code, the active material infeed can be switched allowing the extruder to switch between two materials. Figure [11] shows the assembled system and Figure [12] shows a completed multi-material print. 


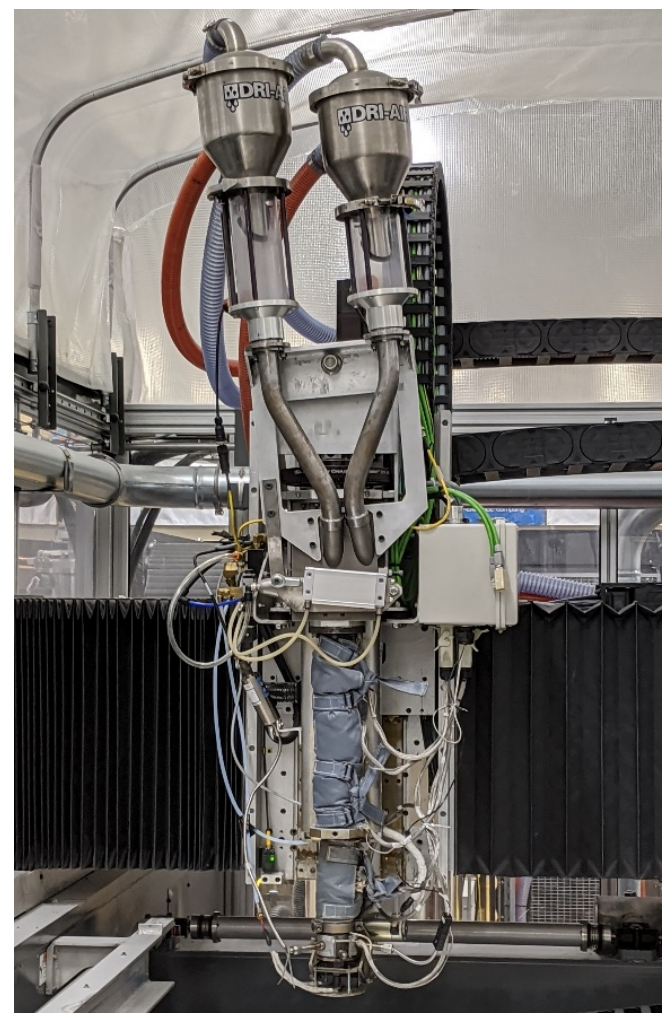

Figure 11. Multi-material system installed on BAAM. Note the two silver hoppers that house and feed the extender two different materials

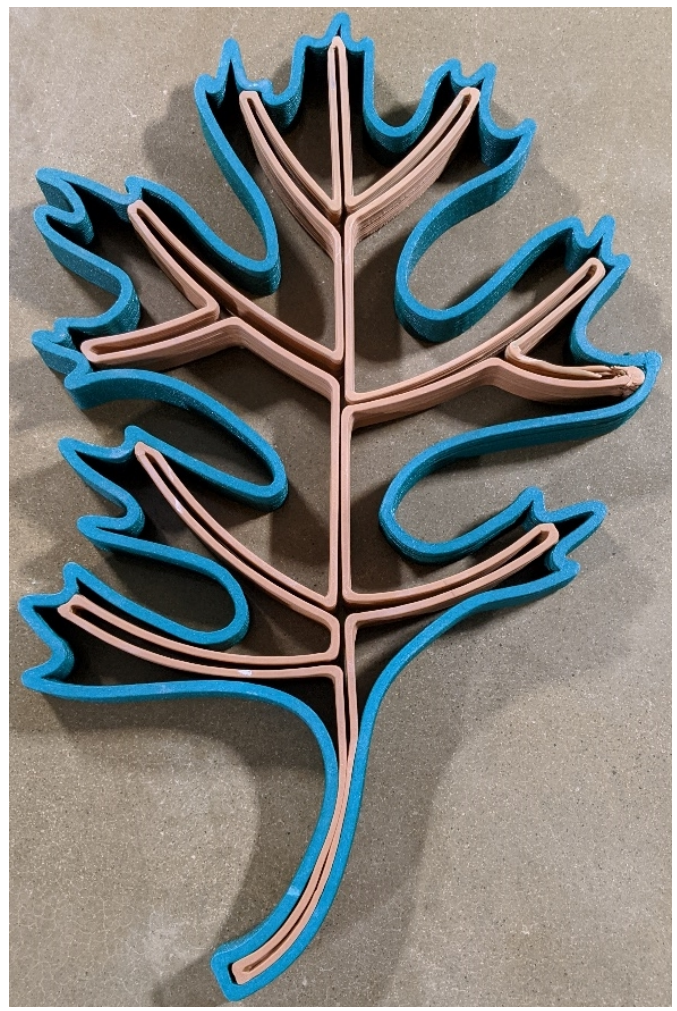

Figure 12. A two-color oak leaf printed using the multi-material system 
The final task for the third year was multi-nozzle printing. ORNL primarily uses a 0.3 " diameter nozzle for printing on the BAAM. This size is a good balance between output bead width and printing speed. However, a 0.3 " nozzle creates a 0.15 " layer height which is a low resolution. For higher resolution parts, a lower layer height is needed, which adds more layers to the print and slows down the print. To circumvent this issue, ORNL developed a multi-nozzle system that attaches to the extruder and allows the system to change the nozzle diameter during the print. This allows for a small, high resolution, nozzle to be used for the perimeter of the part and a big, low resolution, nozzle to be used to fill the interior of the part. Figure [13] shows the system and Figure [14] shows a part printed with this dual nozzle system.

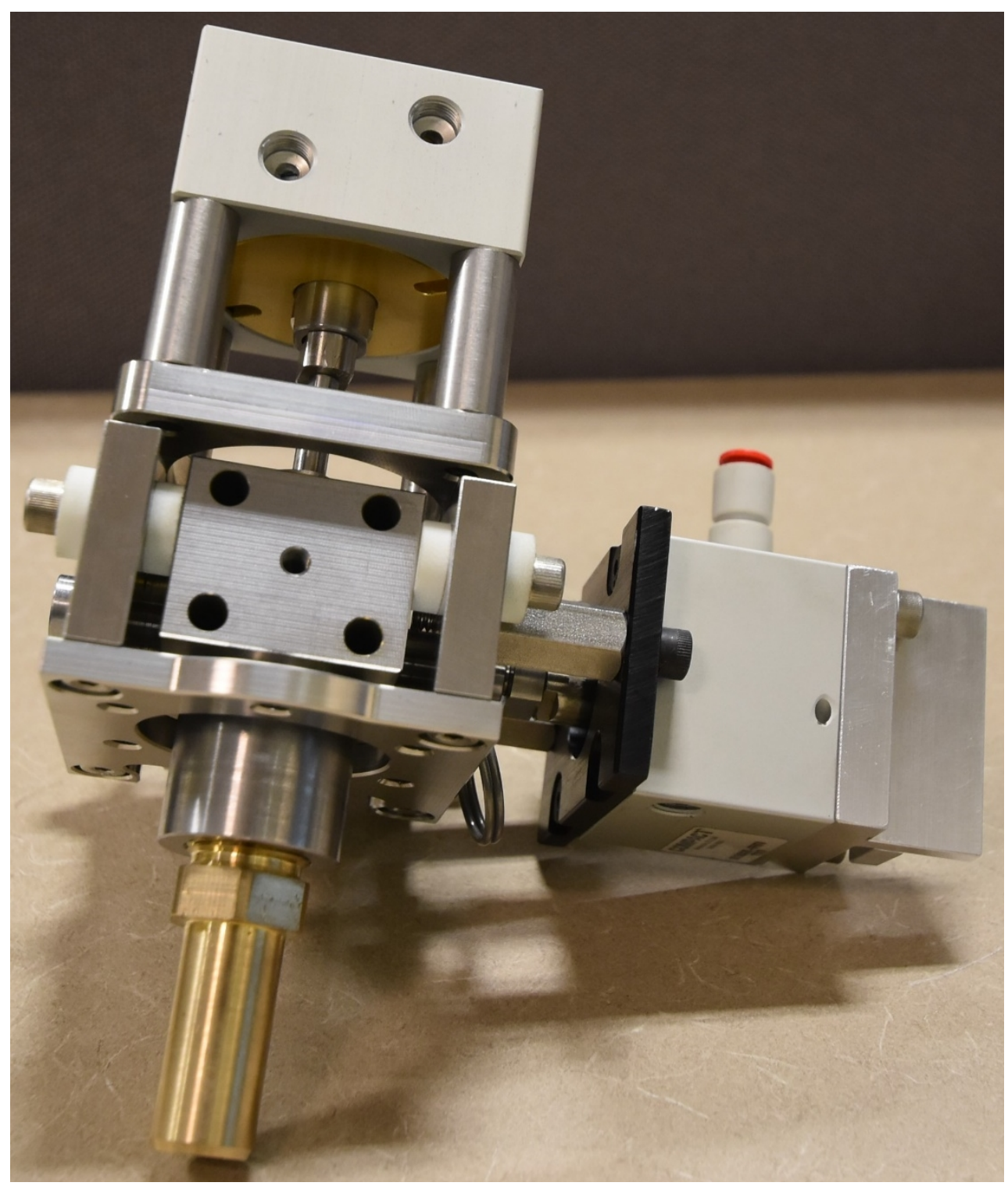

Figure 13. Dual Port Nozzle assembly 


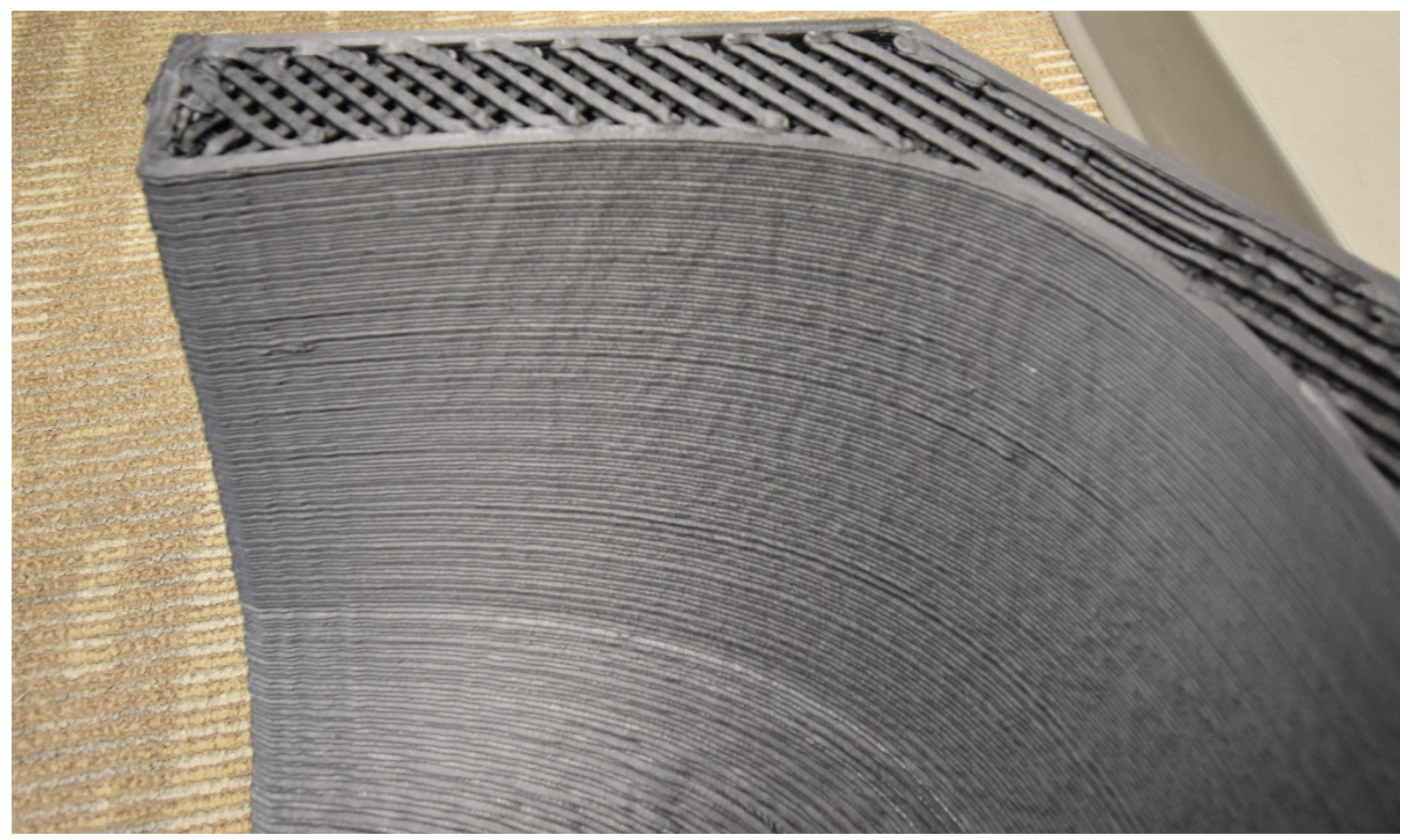

Figure 14. A print with the dual port nozzle showing high resolution exterior and low resolution interior

\subsection{IMPACTS}

The success of this CRADA between ORNL and CI is not just beneficial to CI but will be beneficial to all of the large format additive manufacturing companies. ORNL has published about all the aforementioned innovations including multiple publications in the Additive Manufacturing Journal. CI has published software updates to all users based on the developments at ORNL and is actively working on commercializing the hardware developments. CI has sold BAAM systems during the period of this CRADA including a sale to Additive Engineering Solutions (AES), a company operating as a BAAM service bureau.

\subsection{CONCLUSIONS}

This second CRADA with CI resulted in many new systems being developed for the BAAM system giving CI new capabilities and improving the overall performance of the system. The first year resulted in methods for autonomous fault detection. The second year brought faster higher resolution printing, layer to layer inspection, and five-axis deposition. The third and final year saw an integrated pick and place system as well as multi-material and multi-nozzle printing. This three-year period yielded significant innovations and improvements to the BAAM system that $\mathrm{CI}$ is now able to market to current and future BAAM owners. This successful CRADA will not only benefit CI, but the entire large format additive manufacturing market. 


\section{PARTNER BACKGROUND}

Since Cincinnati's founding in the late 1890's as The Cincinnati Shaper Company, Cincinnati, Incorporated has built its reputation on three principles: innovation, performance, and endurance. They built on their leadership with those early machines to begin the manufacture of metal fabrication equipment in the early 1920 's, and this remains their primary focus. They are one of a handful of U.S.-based, build-to-order machine tool manufacturers, and have shipped more than 50,000 machines in over 100 years of operation. From their modern 500,000-square-foot plant and technical center on a $600+$ acre site near Cincinnati, Ohio, they engineer and build machines to the standard of ruggedness required in the North American market - with premium engineering features that stand up to years of rigorous use in demanding environments. 